\title{
PRODUTIVIDADE DE RAÍZES DE BATATA-DOCE DESTINADA A PRODUÇÃO DE ETANOL
}

\author{
Amarílis Beraldo Rós
}

Agência Paulista de Tecnologia dos Agronegócios, Polo Regional da Alta Sorocabana, Presidente Prudente, São Paulo. E-mail: amarilis@apta.sp.gov.br

\begin{abstract}
RESUMO
A batata-doce apresenta ampla possibilidade de utilização, podendo, inclusive, ser utilizada na obtenção de etanol. Assim, nesse trabalho objetivou-se avaliar a produtividade de raízes de cultivares de batata-doce desenvolvidas para a produção de etanol em Presidente Prudente/SP. O delineamento experimental foi em blocos ao acaso, com sete tratamentos e quatro repetições. Os tratamentos foram sete cultivares de batata-doce, sendo cinco destinadas a produção de etanol (Duda, Carolina Vitória, Marcela, Beatriz e Bárbara) e duas voltadas ao consumo in natura (Londrina e Uruguaiana). As cultivares apresentaram diferenças significativas em todas as características analisadas: produtividades total e comercial, massa seca e formato de raiz. Duda, Londrina, Uruguaina e Bárbara apresentam potencial de produtividade total acima de $40 \mathrm{t} \mathrm{ha}^{-1} \mathrm{na}$ região. Duda e Uruguaiana são as mais indicadas pois apresentam as maiores produções de massa seca por unidade de área.
\end{abstract}

Palavras Chave: Ipomoea batatas; massa seca; formato de raiz.

\section{YIELD OF SWEET POTATO ROOTS FOR ETHANOL PRODUCTION}

\begin{abstract}
The sweet potato is a crop with wide possibility of use, and it can even be used to obtain ethanol. Thus, this study aimed to evaluate the yield of sweet potato roots developed for ethanol production in Presidente Prudente city/ SP state. The experimental design was in randomized blocks, with seven treatments and four replications. The treatments were seven sweet potato cultivars, five of them are used for ethanol production (Duda, Carolina Vitória, Marcela, Beatriz and Bárbara) and two for fresh market (Londrina and Uruguaiana). The cultivars presented significant differences in all characteristics studied: total and commercial yield, dry mass and root shape. The potential total yield of Duda, Londrina, Uruguaina and Bárbara was above $40 \mathrm{t} \mathrm{ha}^{-1}$ in the region. Duda and Uruguaiana are the most indicated because they present the highest yields of dry mass per area unit.
\end{abstract}

Keywords: Ipomoea batatas; dry mass; root shape.

\section{INTRODUÇÃO}

A batata-doce é uma planta originária da América Latina e suas raízes tuberosas ocupam o sexto lugar entre os alimentos mais produzidos no mundo (INTERNATIONAL POTATO CENTER, 2010). A cultura produz grande quantidade de alimento por unidade de área e de tempo, aproveitando curtos períodos de chuva e resistindo a períodos de seca, além de apresentar boa produtividade em solos com baixa fertilidade (INTERNATIONAL POTATO CENTER, 2008).

A cultura apresenta ampla possibilidade de utilização. Suas ramas podem ser aproveitadas na alimentação animal e suas raízes podem ser consumidas na forma in natura ou processada. Além da produção de alimentos, a batata-doce pode ser utilizada na obtenção de etanol. Segundo 
Silveira (2008a), com o melhoramento genético, algumas cultivares de batata-doce têm apresentado índices de produção etílica por hectare duas vezes maior que os de cana de açúcar. Enquanto uma tonelada de cana-de-açúcar gera 67 litros de etanol, essa quantidade de batatadoce chega a produzir 130 litros do combustível (CASTRO; EMYGDIO, 2009).

Pesquisadores da Universidade Federal do Tocantins desenvolveram cultivares de batatadoce voltadas para indústria de etanol, adaptadas às condições do Tocantins. Duda é uma dessas cultivares e apresenta produtividade média de 65,5 t/ha, em ciclo de 6 meses; seu teor de matéria seca é de 40,4\%, podendo render 161 litros de etanol por tonelada de raiz (SILVEIRA, 2008b).

A utilização de fontes alternativas de matéria prima para produção de etanol é necessária, dada à dimensão territorial do Brasil. E a diversificação da matriz bioenergética representa oportunidades de emprego e geração de renda (SILVEIRA et al., 2007).

Assim, nesse trabalho objetivou-se avaliar a produtividade de raízes de cultivares de batata-doce desenvolvidas para a produção de etanol em Presidente Prudente/SP, região onde a cultura apresenta expressiva importância.

\section{METODOLOGIA}

O trabalho foi realizado na Agência Paulista de Tecnologia dos Agronegócios - Polo Regional da Alta Sorocabana, no município de Presidente Prudente, a 22 $11^{\prime}$ de latitude S e 51을 23' de longitude W Gr. com 424,29 m de altitude. O clima é Aw, segundo classificação de Köppen, apresentando duas estações bem definidas: verão quente e úmido e inverno ameno e seco.

O solo foi classificado como Argissolo Vermelho Amarelo, textura arenosa no horizonte A. Foi realizada amostragem de solo na área no momento do plantio da batata-doce para determinação de atributos químicos, com os seguintes resultados na camada de $0-20 \mathrm{~cm}$ de profundidade: $\mathrm{pH}\left(\mathrm{CaCl}_{2} 1 \mathrm{~mol} \mathrm{~L}^{-1}\right)$ 5,2; 45,3 mg dm${ }^{-3}$ de $\mathrm{P}_{\text {Mehlich; }}, 9 \mathrm{~g} \mathrm{dm}^{-3}$ de $\mathrm{C} ; 2,7 \mathrm{cmol}_{\mathrm{c}} \mathrm{dm}^{-3}$ de $\mathrm{H}+\mathrm{Al} ; 0,3 \mathrm{cmol}_{\mathrm{c}} \mathrm{dm}^{-3}$ de $\mathrm{K} ; 1,5 \mathrm{cmol}_{\mathrm{c}} \mathrm{dm}^{-3}$ de $\mathrm{Ca} ; 1,0 \mathrm{cmol}_{\mathrm{c}} \mathrm{dm}^{-3}$ de $\mathrm{Mg} ; 50,1 \%$ de saturação por bases.

O delineamento experimental foi em blocos ao acaso, com sete tratamentos e quatro repetições. Os tratamentos foram constituídos por sete cultivares de batata-doce, sendo cinco destinadas a produção de etanol (Duda, Carolina Vitória, Marcela, Beatriz e Bárbara) e duas voltadas ao consumo in natura (Londrina e Uruguaiana) com alta produtividade na região de Presidente Prudente/SP.

Para a instalação do experimento, a área foi preparada por meio de aração, gradagem e confecção de leiras, com aproximadamente $0,35 \mathrm{~m}$ de altura. Cada parcela de $21,6 \mathrm{~m}^{2}$ foi constituída por três linhas distanciadas $0,9 \mathrm{~m}$ onde foram plantadas 20 ramas de $0,3 \mathrm{~m}$ cada, oriundas de ponteiros de plantas de batata-doce, espaçadas a cada 0,4 $\mathrm{m}$, o que correspondeu a 27.777 plantas ha ${ }^{-1}$. A área útil foi constituída pela porção que continha as 18 plantas centrais da leira do meio. O plantio ocorreu em janeiro de 2017. Após 180 dias do plantio, foi avaliada a produtividade total de raízes (raízes com massa igual ou superior a $80 \mathrm{~g}$ ). E para avaliação das cultivares voltadas a produção de etanol como possíveis fornecedoras de raízes para consumo in natura, também foi quantificada a produtividade comercial. Na produtividade comercial foram consideradas as raízes tuberosas com massa igual ou superior a $150 \mathrm{~g}$ e menor que $1000 \mathrm{~g}$ e com formato uniforme e liso.

Também foram avaliados massa seca, comprimento médio, diâmetro médio e relação comprimento/diâmetro das raízes tuberosas consideradas comerciais.

Os dados obtidos foram submetidos a análises de variância e as médias comparadas pelo teste de Tukey, a 5\% de probabilidade de erro. 


\section{RESULTADOS}

As cultivares apresentaram diferenças significativas em todas as características analisadas: produtividades total e comercial, massa seca (Tabela 1), comprimento, diâmetro e relação comprimento/diâmetro médio de raízes (Tabela 2 ).

Tabela 1. Produtividades total e comercial e massa seca de raízes tuberosas de batata-doce em função de diferentes cultivares.

\begin{tabular}{lcccc}
\hline Cultivar & \multicolumn{2}{c}{ Produtividade } & Massa seca (\%) & $\begin{array}{c}\text { Massa seca } \\
\left(\mathrm{t} \mathrm{ha}^{-1}\right)\end{array}$ \\
\hline Duda & $46,3 \mathrm{~A}$ & $16,8 \mathrm{BC}$ & $34,2 \mathrm{~A}$ & $15,8 \mathrm{~A}$ \\
\hline Londrina & $43,0 \mathrm{AB}$ & $29,7 \mathrm{~A}$ & $22,9 \mathrm{C}$ & $9,9 \mathrm{BC}$ \\
\hline Uruguaiana & $40,8 \mathrm{AB}$ & $24,1 \mathrm{AB}$ & $29,8 \mathrm{~B}$ & $12,2 \mathrm{AB}$ \\
\hline Bárbara & $39,3 \mathrm{AB}$ & $4,7 \mathrm{D}$ & $28,6 \mathrm{~B}$ & $11,2 \mathrm{~B}$ \\
\hline Carolina Vitória & $32,7 \mathrm{BC}$ & $11,2 \mathrm{CD}$ & $33,7 \mathrm{~A}$ & $11,0 \mathrm{~B}$ \\
\hline Beatriz & $23,7 \mathrm{CD}$ & $9,5 \mathrm{CD}$ & $30,1 \mathrm{~B}$ & $7,2 \mathrm{CD}$ \\
\hline Marcela & $19,0 \mathrm{D}$ & $8,9 \mathrm{CD}$ & $30,0 \mathrm{~B}$ & $5,7 \mathrm{D}$ \\
\hline CV $(\%)$ & 13,2 & 22,1 & 2,9 & 13,9 \\
\hline
\end{tabular}

Duda apresentou maior produtividade total que Carolina, Beatriz e Marcela. As cultivares utilizadas na região (Londrina e Uruguaiana) e Bárbara apresentaram produtividade total semelhante a Duda, mas superior à Beatriz e Marcela.

Quanto à produtividade comercial, o coeficiente de variação (CV) foi elevado, visto que as cultivares destinadas a indústria apresentaram grande variação na característica entre as parcelas. As cultivares com as maiores produtividades comerciais foram Londrina e Uruguaiana, embora Duda tenha apresentado valor semelhante a Uruguaiana. Bárbara embora tenha elevada produtividade total, apresentou produtividade comercial baixa $\left(4,7 \mathrm{t} \mathrm{ha}^{-1}\right)$.

As cultivares apresentaram diferenças no teor de massa seca, sendo que Duda e Carolina apresentaram os maiores valores e Londrina o menor. Assim, relacionando-se a produtividade total com o teor de massa seca, Duda produziu a maior quantidade de massa seca por unidade de área, embora não tenha diferido significativamente de Uruguaiana. O pior desempenho foi verificado em Marcela $\left(5,7 \mathrm{t} \mathrm{ha}^{-1}\right)$, que não diferiu estatisticamente de Beatriz.

Tabela 2. Comprimento, diâmetro e relação comprimento/diâmetro médio de raízes tuberosas de batata-doce em função de diferentes cultivares.

\begin{tabular}{lccc}
\hline Cultivar & Comprimento médio $(\mathrm{cm})$ & Diâmetro médio $(\mathrm{cm})$ & Comprimento/diâmetro \\
\hline Duda & $12,1 \mathrm{C}$ & $6,6 \mathrm{AB}$ & $1,8 \mathrm{C}$ \\
\hline Londrina & $18,8 \mathrm{~A}$ & $5,7 \mathrm{~B}$ & $3,3 \mathrm{~A}$ \\
\hline Uruguaiana & $16,9 \mathrm{AB}$ & $6,6 \mathrm{AB}$ & $2,6 \mathrm{~B}$ \\
\hline Bárbara & $16,1 \mathrm{AB}$ & $6,6 \mathrm{AB}$ & $2,4 \mathrm{BC}$ \\
\hline Carolina & $14,6 \mathrm{BC}$ & $5,9 \mathrm{~B}$ & $2,5 \mathrm{~B}$ \\
\hline Beatriz & $16,4 \mathrm{AB}$ & $6,7 \mathrm{AB}$ & $2,5 \mathrm{BC}$ \\
\hline Marcela & $15,7 \mathrm{AB}$ & $7,1 \mathrm{~A}$ & $2,3 \mathrm{BC}$ \\
\hline CV $(\%)$ & 8,5 & 7,0 & 11,3 \\
\hline
\end{tabular}

Com relação ao comprimento médio das raízes consideradas comerciais, Londrina apresentou raízes com valor superior as cultivares Duda e Carolina, mas não diferiu estatisticamente de Uruguaiana, Bárbara, Beatriz e Marcela. 
O diâmetro médio das raízes comerciais também diferiu entre as cultivares. Marcela apresentou maior valor que Londrina e Carolina.

Por fim, na relação comprimento/diâmetro foi verificado que a cultivar Londrina apresenta formato mais alongado que as demais cultivares, enquanto Duda, o formato mais arredondado.

\section{DISCUSSÃO}

Era esperado que os materiais diferissem quanto às produtividades total e comercial de raízes tuberosas pois diferentes cultivares apresentam potenciais de produção diferentes, bem como também respondem de maneira distinta a condições edafoclimáticas diversas. Andrade Junior et al. (2012), Martins et al. (2012) e Vieira et al. (2015) também verificaram valores de produtividade semelhantes entre algumas cultivares e bastante diferentes entre outras.

A produtividade total obtida pelas cultivares Carolina Vitória e Bárbara foi semelhante ao relatado por Silveira (2008b), no entanto Duda, Marcela e Beatriz apresentaram produtividade inferior ao potencial das mesmas, visto que, segundo Silveira (2008b), as produtividades médias são 65,$5 ; 36,8$ e 43 t ha ${ }^{-1}$, respectivamente. Considerando-se que Londrina e Uruguaiana apresentaram produtividade superior a $40 \mathrm{t} \mathrm{ha}^{-1}$, valor considerado por Rós et al. (2012) como elevado para as cultivares, pode-se deduzir que as condições edafoclimáticas estavam favoráveis para a cultura. Dessa forma, devem ser realizados mais estudos na região para que sejam verificados os fatores que não permitiram que o potencial de algumas cultivares destinadas a indústria fosse atingido.

Como esperado para a produtividade comercial, Londrina e Uruguaiana apresentaram os maiores valores, embora a última não tenha diferido de Duda. Londrina e Uruguaiana são cultivares selecionadas para a produção de batata-doce para consumo in natura, então sua produtividade comercial deve ser elevada. Os demais materiais foram selecionados para a produção de raízes para utilização industrial, e, portanto, a produção de raízes com aspectos comerciais não é importante.

O teor da massa seca pode ser semelhante entre cultivares (ANDRADE JUNIOR et al., 2012), mas frequentemente apresentam valores diferentes. Martins et al. (2012), comparando 50 clones, separou-os em quatro grupos de faixa de porcentagem de massa seca, sendo que os valores variaram de $39,13 \%$ a $24,52 \%$. A variação na característica no presente trabalho foi inferior a observada por Martins et al. (2012) e os teores encontrados por este para os clones Duda, Marcela, Beatriz e Bárbara (36,6; 36,0; 32,8 e 35,7\%, respectivamente) foram superiores aos obtidos $(34,2 ; 30,0 ; 30,1$ e $28,6 \%$, respectivamente).

O teor de massa seca influencia o rendimento por tonelada de raiz na produção de etanol. Assim, elevada produtividade de raízes associada a elevado teor de massa seca é um aspecto importante na escolha de cultivares. Duda é um material que apresentou essa característica, o que resultou na maior produtividade de massa seca por unidade de área $\left(15,8 \mathrm{t} \mathrm{ha}^{-1}\right)$, embora esse valor não tenha diferido significativamente de Uruguaiana $\left(12,2 \mathrm{t} \mathrm{ha}^{-1}\right)$.

Quanto às características relacionadas ao formato das raízes comerciais (comprimento, diâmetro e relação comprimento/diâmetro) os clones apresentaram diferentes valores, o que está relacionado ao genótipo dos materiais. Em estudo sobre formato de raízes tuberosas de 16 clones de batata-doce, Cardoso et al. (2005) verificaram que houve diferença no comprimento médio de raízes entre os clones, no entanto, o diâmetro médio de raízes e o formato das raízes não variou entre os materiais.

Todas as cultivares, com exceção de Duda, apresentaram relações comprimento/diâmetro semelhantes a Uruguaiana. Londrina apresentou maior valor nesta característica. O formato das 
raízes é uma característica importante para sua venda para consumo in natura, pois na região há preferência por raízes mais alongadas.

\section{CONCLUSÕES}

As cultivares apresentam diferenças quanto à produtividade, massa seca e formato de raiz.

As cultivares para indústria, em geral, apresentam baixa produtividade comercial.

Duda, Londrina, Uruguaiana e Bárbara apresentam potencial de produtividade acima de 40 $\mathrm{t}$ ha ${ }^{-1}$ na região.

Duda e Uruguaiana são as variedades mais indicadas para produção de etanol pois apresentam as maiores produções de massa seca por unidade de área.

\section{REFERÊNCIAS}

ANDRADE JÚNIOR, V.C.; VIANA, D.J.S.; PINTO, N.A.V.D.; RIBEIRO, K.G.; PEREIRA, R.C.; NEIVA, I.P.; AZEVEDO, A.M.; ANDRADE, P.C.R. Características produtivas e qualitativas de ramas e raízes de batata-doce. Horticultura Brasileira, v.30, n.4, p.584-589, 2012. https://doi.org/10.1590/S0102$\underline{05362012000400004}$

CARDOSO, A.D.; VIANA, A.E.S.; RAMOS, P.A.S.; MATSUMOTO, S.N.; AMARAL, C.L.F.; SEDIYAMA, T.; MORAIS, O.M. Avaliação de clones de batata-doce em Vitória da Conquista. Horticultura Brasileira, v.23, n.4, p.911-914, 2005. https://doi.org/10.1590/S0102-05362005000400009

CASTRO, L.A.S.; EMYGDIO, B.M. Batata-doce para produção de biocombustível. Portal do agronegócio. EMBRAPA Clima temperado, Pelotas, RS, 2009. Disponível em: http://www.infobibos.com/Artigos/2009 4/BatataDoce/Index.htm Acesso em: 14 jul. 2017.

INTERNACIONAL POTATO CENTER. Facts and figures about sweetpotato. Lima, 2010. Disponível em: $\quad$ http://nkxms1019hx1xmtstxk3k9sko.wpengine.netdna-cdn.com/wpcontent/uploads/PDF/005448.pdf Acesso em 14 ago. 2016.

INTERNATIONAL POTATO CENTER. Annual report 2008: sweetpotato as a health benefit. Lima, 2008. Disponível em: <http://sweetpotatoknowledge.org/ sweetpotatointroduction/importance/Sweetpotato\% 20as\%20a\%20health\%20benefit.pdf\#>. Acesso em: 17 ago. 2012.

MARTINS, E.C.A.; PELUZIO, J.J.; COIMBRA, R.R.; OLIVEIRA JUNIOR, W. Variabilidade fenotípica e divergência genética em clones de batata doce no estado do Tocantins. Revista Ciência Agronômica, v.43, n.4, p.691-697, 2012. https://doi.org/10.1590/S1806-66902012000400010

RÓS, A.B.; HIRATA, A.C.S.; SANTOS, H.S. Avaliação da produtividade de plantas de batata-doce oriundas de matrizes livres de vírus. Revista Brasileira de Ciências Agrárias, v.7, n.3, p.434-439, 2012. https://doi.org/10.5039/agraria.v7i3a1716

SALLA, D.A.; CABELLO, C. Análise energética de sistemas de produção de etanol de mandioca, cana-de-açúcar e milho. Revista Energia na Agricultura, v.25, n.2, p.32-53, 2010. https://doi.org/10.17224/EnergAgric.2010v25n2p32-53 
SILVEIRA, M.A. (Coord.). Batata-doce: uma nova alternativa para a produção de etanol. In: INSTITUTO EUVALDO LODI/NÚCLEO CENTRAL. Álcool combustível. Brasília: IEL/NC, 2008. p.109122. (Série indústria em perspectiva).

SILVEIRA, M.A. Batata-Doce: A Bionergia da Agricultura Familiar. 2008b. 19p. Disponível em: http://www.abhorticultura.com.br/eventosx/trabalhos/ev 1/PAL11.pdf Acesso em 13 jul. 2017.

SILVEIRA, M.A.; ANDRÉ, C.M.G.; ALVIM, T.C.; DIAS, L.E.; TAVARES, I.B.; SANTANA, W.R.; SOUZA, F.R. A cultura da batata-doce como fonte de matéria-prima para a produção de etanol. Palmas: Universidade Federal do Tocantins, 2007. 45p. (Boletim Técnico).

VIEIRA, A.D.; MIRANDA, V.C.; ALVES, A.F.; TAVARES, A.T.; MOMENTÉ, V.G. Agronomic evaluation of clones of sweet potato with potential for ethanol production. Brazilian Journal of Applied Technology for Agricultural Science, v.8, n.1, p.69-74, 2015. 